Marquette University

e-Publications@Marquette

Psychology Faculty Research and Publications

Psychology, Department of

$1-1-2001$

\title{
Nonlinear Dynamics in Psychology
}

Stephen J. Guastello

Marquette University, stephen.guastello@marquette.edu

Published version. Discrete Dynamics in Nature and Society, Vol. 6, No. 1 (2001): 11-29. DOI. (C) 2001 Hindawi Publishing Corporation. This is an open access article distributed under the Creative Commons Attribution License, which permits unrestricted use, distribution, and reproduction in any medium, provided the original work is properly cited. 


\title{
Nonlinear Dynamics in Psychology
}

\author{
STEPHEN J. GUASTELLO* \\ Marquette University
}

(Received 2 February 2000)

\begin{abstract}
This article provides a survey of the applications of nonlinear dynamical systems theory to substantive problems encountered in the full scope of psychological science. Applications are organized into three topical areas - cognitive science, social and organizational psychology, and personality and clinical psychology. Both theoretical and empirical studies are considered with an emphasis on works that capture the broadest scope of issues that are of substantive interest to psychological theory. A budding literature on the implications of NDS principles in professional practice is reported also.
\end{abstract}

Keywords: Nonlinear dynamics; Chaos; Cognition; Organizations; Personality; Psychotherapy; Social psychology

The purpose of this article is to provide a survey of the recent developments in the application of nonlinear dynamical systems (NDS) theory to theoretical and practical problems encountered in the domain of psychology. For the benefit of nonpsychologists, it is important to note that the scope of psychology is expansive. Introductory textbooks are typically organized around the following themes: brain physiology and behavior, psychophysics, sensation, perception, learning, memory, cognition, intelligence and mental measurement, development, social psychology, motivation and emotion, personality of normal range people, abnormal psychology, psychotherapy and counseling, and industrial-organizational psychology. At the other end of the professional spectrum, the largest professional organization for psychologists, the American psychological Association, contains more than 50 topical interest groups in addition to its general membership core.

Only about half of academic psychologists can be found in university psychology departments, according to a recent report (Brookhart, 2000). Psychologists are often found in departments or schools of education, communication, medicine or health sciences, business, law, and occasionally engineering. It is against that backdrop that interdisciplinary studies of NDS have emerged. Although the literature is already large and growing rapidly, the density of coverage in any

*Address for correspondence: Dept. Psychology, Marquette University, P.O. Box 1881, Milwaukee, WI 53201-1881 USA. Tel.: 414-288-6900, Fax: 414-288-5333, e-mail: stephen.guastello@marquette.edu 
particular topic area named above is thin. For that reason it would be unwise to engage a critical reviews of topic areas that are changing quickly, and it would be pretentious to propose to include the pedantic details of the literature as it is known now. Rather, I engage a more modest objective of providing a survey of that literature with an emphasis on the books and articles within the NDS-psychology areas that have the broadest scope.

\section{THE BROAD ORGANIZATION OF NDS IN PSYCHOLOGY}

The early years of NDS in psychology can be traced back to catastrophe theory (Thom, 1975), its widespread conceptual applications (Zeeman, 1977), a special issue of Behavioral Science (Cobb and Ragade, 1978), and a parade of articles that subsequently appeared in that journal. After a period of waning in the later 1980s, the broader history of NDS, which dates back to works by Poincaré, Cantor and Lyapunov in the 19th century, collided with psychological theory in an extensive way. Psychologist F. Abraham, mathematician R. Abraham, and graphic artist Shaw (1990) teamed up to produce a landmark wellreasoned speculation on the possible applications of NDS to psychology in most of its content domains. The roster of dynamics now included attractors of varying types, bifurcations in several forms, chaos, fractals, and self-organization.

The Society for Chaos Theory in Psychology and Life Sciences was founded in 1991 in San Francisco. The scope of its interest in dynamics has expanded to include neural nets, evolutionary computation, cellular automata, and other related forms of dynamics. The scope of its substantive interests extends from microbiology to macroeconomics, although its productivity in psychology is perhaps its most prominent feature. Its principal contributions to the literature consists of three edited collections (Abraham and Gilgen, 1995; Robertson and Combs, 1995; Sulis and Combs,
1996) and the research journal Nonlinear Dynamics, Psychology, and Life Sciences, the inaugural issue of which appeared in January, 1997. (See Guastello, 1997, for the editorial purview.) Two later edited collections, which were orchestrated by the Society's European counterparts, should be considered historically significant as well (Guindani and Salvadori, 1998; Tschacher and Dauwalder, 1999).

Each of the foregoing publications unpacks many interesting authors with vibrant lines of research. The prominent themes among them are considered next, but they are not limited to Society publications. The path of least resistance suggests that the specific works in psychology should be organized into three themes: cognitive science, social organizations, and clinical studies. I will forego a section on neuroscience, largely because of the continuity of that topic with non-psychological studies. Works by Freeman (1995); Basar (1998, 1999); Waters (1999); Ferro Milone, Minelli and Turicchia (1998) and Minelli and Turicchia (1999) should be considered significant contributions in that area, however.

\section{COGNITIVE SCIENCE APPLICATIONS}

Current thinking in NDS theory is that consciousness is an integrated process consisting of psychophysics and sensation processes, perception, cognition, learning, memory, and action. Although it has been convenient to think of these processes as separate entities, the separations are somewhat contrived. Similarly, real-world stimuli largely consist of continuous flows and random shocks.

Figure 1 displays the set of relationships that are thought to exist among cognitive processes as seen by an outside observer (researcher). Starting at the upper right, an incoming flow of stimuli is first encountered by the human processes of sensation and psychophysical transduction. Perception processes organize the incoming stimuli into recognizable wholes through combinations of learned 


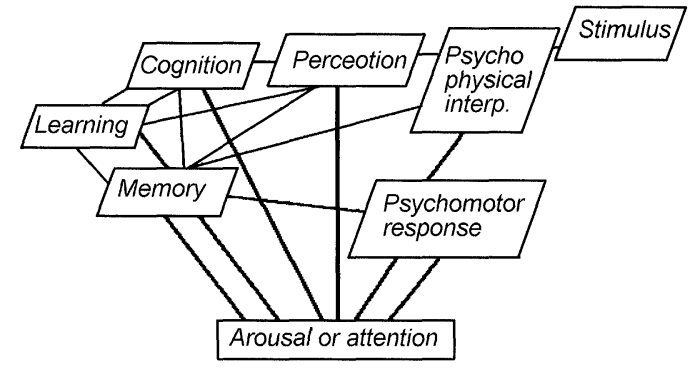

FIGURE 1 Integrative network of cognitive processes.

regimes and innate capabilities. Cognition involves a wide range of processes by which the recognized patterns are compared, associated with information already in memory, transformed in simple or complicated ways, and organized into responses. Learning involves one or more processes by which the individual organism acquires knowledge, skills, abilities, and adaptive responses. Memory pertains to how what is learned is organized and stored, and without which learning would be impossible. The psychomotor response section of the model signifies how the response is produced by the individual (or not produced).

The heavy black connections between the boxes in Figure 1 indicate information flows that have been acknowledged in conventional thinking as portrayed in introductory textbooks. The light gray connections acknowledge additional patterns of information flow that characterize the complex systems nature of human cognition. For instance, cognition-action patterns are now studied as "autonomous agents" (Tschacher and Dauwalder, 1999). The heavy gray connections indicate a connection to a general driving force of arousal or attention. Attention processes limit the extent, and probably the speed, by which a combination of the foregoing cognitive processes will be engaged.

Each function depicted in Figure 1 has lent itself to empirical study of nonlinear dynamical processes (Clayton and Frey, 1996, 1997; Davids, Button and Bennett, 1999; Goertzel, 1993a, 1993b, 1994, 1997; Gregson 1992, 1995, 1998, 1999; Guastello, 1995; Kahonen, 1989; Kelso, 1995;
Port and van Gelder, 1995; Porter and Hogue, 1998; Pressing, 1999; Ward and West, 1998). There have been substantial theoretical contributions as well (Combs, 1995; Gilgen, 1995; Hardy, 1998; MacCormac and Stamenov, 1996; Sulis, 1997; Tschacher and Dauwalder, 1999).

\section{Psychophysics}

The landmark contribution from the 19th century, due to Weber and Fechner, was to find the nonlinear relationships that exist between the strength of physical stimuli, such as brightness of lights, loudness of sounds, and so forth. Those relationships carried with them concepts of the absolute threshold and difference threshold, which initially were conceptualized as numbers that generalized across humans.

The landmark contribution by the middle 20th century, due to Stevens, was the formation of signal detection theory. The threshold concepts were now regarded as stochastic entities, and physical stimuli were detected relative to noise. To be brief, it became possible to separate the sensory acuity of the individual from experimental response set, and from the properties of the stimuli themselves. The study of simple decision errors gave way to the foundation of decision theory, which today involves decisions of a much more complex nature.

The NDS contributions to psychophysics are largely the work of Gregson (1992, 1995, 1998, 1999). They address additional questions not considered previously such as what happens when: stimuli contain multiple parameters as in the taste of wine, stimuli have complex decay functions, and stimuli are generated. The mathematical model that is central to the new nonlinear psychophysics is the gamma recursion formula:

$$
Y_{j+1}=-a\left(Y_{j}-1\right)(Y j-\mathrm{i} e)(Y j+\mathrm{i} e),
$$

(Gregson, 1992, p. 20) where $Y$ is the strength of a response at $j$ points in time, $a$ is a control parameter representing signal strength, $e$ is a 
situational control parameter, and $i$ is the imaginary number $(-1)^{1 / 2}$. The gamma function is a cubic variant of the logistic map, and expands into real and imaginary response components. It expands further into multiparameter signal and response functions.

\section{Perception}

Psychologists have historically paid great attention to optical illusions with the thinking that illusions betray underlying invariant processes of how the mind, and by inference the brain, functions. NDS approaches to the study of perceptual illusions date back to Stewart and Peregoy (1983) and Ta'eed, Ta'eed and Wright (1988), who used a cusp catastrophe model for the process:

$$
d f(y) / d y=y^{3}-b y-a
$$

where $y$ is the response on the continuum between selecting one perceptual image over the other, $b$ is the bifurcation parameter representing the total amount of detail in the ambiguous pictorial stimuli, and $a$ is the asymmetry parameter representing a bias in the pictorial details toward one perceived image over another. Guastello (1995) also suggested that the cusp model for ambiguous stimuli transfer well to the study of more complex decisions, such as those made by juries in legal proceedings.

The newer wave of NDS research in this area targets multistable response patterns more generally, including the classic ambiguous stimuli used in the experiments named above (Haken, 1999; Kelso, 1995; Porter and Hogue, 1998). The favored mathematical model is the GinzbergLandau model of phase transitions:

$$
f(y)=y^{4} / 4-y^{2} / 2-a y
$$

A quick look, however, indicates that Eq. (3) is a potential function for the cusp catastrophe model where the bifurcation effect is held constant. This function has been useful, nonetheless, for modeling the organization of motor response patterns and speech configurations in addition to strictly perceptual phenomena.

\section{Learning}

Learning theory in psychology has undergone numerous developments in psychology in the past century. The oldest regime, due to Thorndike, first identified the learning curve, which is a plot of the number of correct responses given by an organism as a function of the number of learning trials. Reinforcement (e.g., feedback, reward, punishment, etc.) given to the learning organism strengthens the probability of the desired response. In the classic experiment, a cat was placed in a puzzle box, from the cat had to figure out how to escape. The cat began to emit a variety of hissing, scratching, and other irrelevant responses until it discovered the pedal on the floor of the box that opened the cage door. With subsequent trials the cat emits fewer irrelevant responses and eventually goes right to the pedal. The explanation for the underlying psychological events was predicated on associations being formed in the "mind" of the cat.

The second regime, due to Pavlov, explored the role of conditioned reflexes, and how natural reflex mechanisms can be shaped into complex behaviors. The explanation for the underlying psychological events (observed mostly from dogs in the early years) was again predicated on associations being formed. The third regime, however, due to Skinner, emphasized the role of reinforcement shaping behavior, where behavior started with ad lib, or operant behaviors. Skinner took a hard core position of not invoking any associationist explanations, or even assuming that a structure of "mind" existed.

The fourth regime grew up alongside and slightly before Pavlov's. Gestalt psychologists, who were best known for their contributions to perception, provided evidence based on primate behavior that learning can occur in one trial. In cases where it does, it is known as insight. Insight is a well-known critical event in the creative thinking 
process. The Gestalt psychologists were also known for the dictum that "The whole is greater than the sum of its parts", which, by some stretches of the imagination, foreshadowed the post-Newtonian, system-wise thinking that characterizes most NDS applications today.

The fifth regime grew up alongside Skinner's approach. Cognitive learning theory, due to Tolman, was based on experiments that showed that the rat knew where the cheese was located in the maze, and in what relative probability. Here learning produced a cognitive map, which denotes spatial representations, along with what we would call expectancy. A substantial amount of cognitive motivation theory (decision-makers gravitate toward options that are associated with the odds of the best results) is based on this line of thinking. Germane to NDS, cognitive motivation theory is essentially the psychological explanation behind why game theory explains a wide range of human phenomena.

The sixth major movement was statistical learning theory, due to Estes, which addressed the issue of whether partial learning can actually occur. According to this view, learning on each trial is partial. The learned elements eventually add up, often quickly, to the final learning objective. The seventh was social learning theory, due to Bandura, which was based on the observation that learning can occur through vicarious learning, i.e., by watching the behavior of others and their outcomes. The most recent regime is implicit learning theory (Seger, 1994), which focuses attention on things that are learned while the learner is trying more deliberately to learn something else.

The NDS interpretation of learning reflects a few different approaches. One centers around neural networks and learning programs. For the most part, this frame of reference does not proffer central equations. If anything, the nonlinear structures are hidden from the observer-research by the computer program executing the neural network simulation, but see Vickers and Lee $(1998,2000)$ for the psychological implications of what neural networks have to offer.
Other approaches reflect a return to associationist thinking. Ideas, behaviors, and the stimuli that trigger them are thought to self-organize into wholes (Gilgen, 1995; Haken, 1999; Kampis, 1991). If the self-organization process is complete, as in the case of a feasible task, the common learning curve would result, which would in turn be characterized as a fixed point attractor, as in Eq. (4):

$$
Z_{2}=\mathrm{e}^{(-a z 1)}
$$

Where $z$ is behavior and $a$ is the Lyapunov exponent which is constrained to negative values (Guastello, 1995; Guastello and Guastello, 1998). We can have a variable, $b$, in the model that sharpens or flattens the inflection in the learning curve, as in Eq. (5):

$$
Z_{2}=b Z_{1} \mathrm{e}^{(-a z 1)} .
$$

In the in event that learning is incomplete, an asymptote does not form, and the exponent in Eq. (4) or (5) is positive. In other words we have chaos before self-organization (Guastello and Guastello, 1998). Figure 2 shows ensembles of learning curves for an experiment involving a difficult task which the learners frequently did not master (Guastello, Bock and Caldwell, 1999). In the left panel, learners were allowed to talk, which would have facilitated learning. In the right panel, talking was not allowed.

The results shown in Figure 2 were actually obtained from a group learning task, which is revisited below under the heading of work group coordination. Implicit learning was involved in that particular task.

\section{Memory}

There is reason to believe that memory is a distributed process that involves many groupings of neurons that are relatively small, and that the temporal patterns of neuron firing contain a substantial amount of information about memory storage processing (Kahonen, 1989). The temporal 

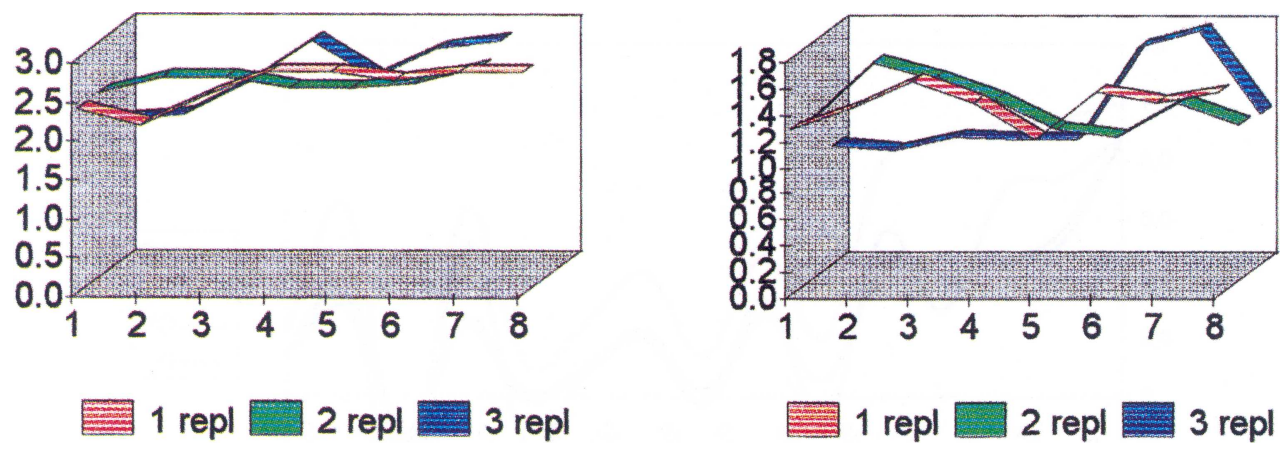

FIGURE 2 Results for a coordination learning task where groups of learners were allowed to talk (left) or not (right), and in which one, two, or three members of the learning group (repl) were replaced during the course of the experiment (from Guastello, Bock and Caldwell, 1999). (See Color Plate I.)

dynamics of memory experiments can be analyzed for two broad classes of information. Inter-trial analyses would indicate whether and how the response to one experimental trial would impact on the subsequent responses. While inter-trial response times have been traditionally regarded as random or probabilistic processes, dynamical analyses indicates that is not the case, and that modicum of structure and long-term patterning is evident (Clayton and Frey, 1996, 1997). On the other hand, the meaning of those patterns is yet to be revealed. Intra-trial analyses of memory experiment data would provide information on the cue encoding, retrieval, and decision processes.

Figure 3 depicts the results from a memory experiment by Clayton and Frey (1997) in which

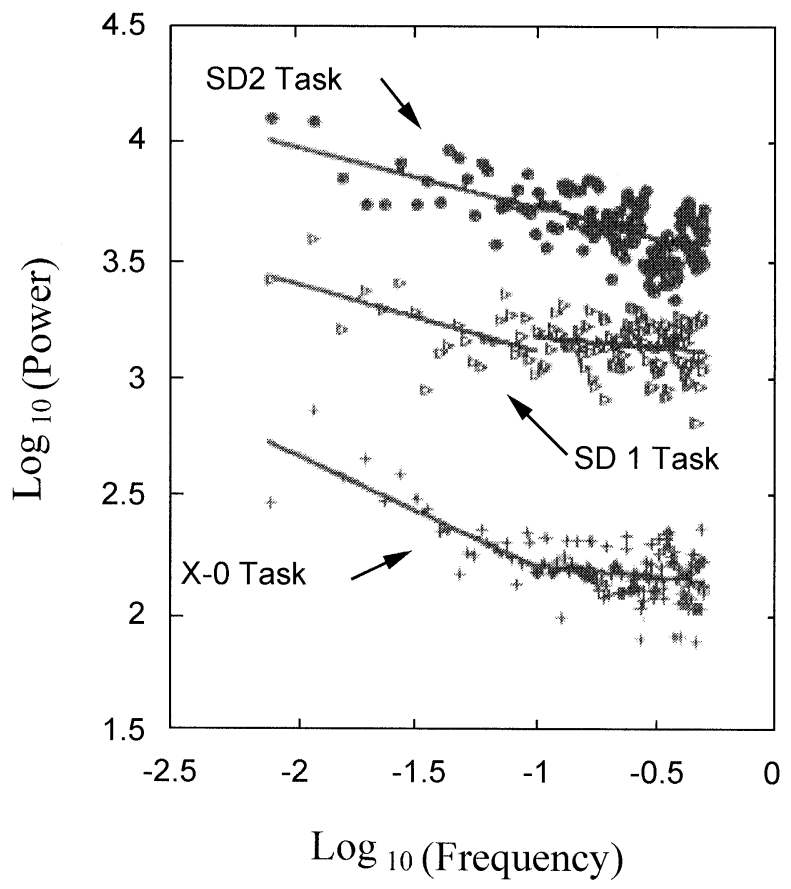

FIGURE 3 Power spectra for response series in memory tasks with low, medium, and high levels of memory demand. 
the researchers examined power spectra from time of response times from a set of memory tasks. The three tasks varied in memory load; the task labeled $\mathrm{X}-0$ required the least load, and SD2 required the greatest. Three spectra were obtained, which corresponded to the three memory loads. Similar FFT results were obtained for each series, however. An important conclusion from the experiment was that the noise in the time series of responses did not correspond to a plethora of uncontrolled variables, as mental measurement theorists have historically assumed. Rather, there was no need to assume that a complex highdimensional system was involved in the generation of "mental noise".

\section{Cognition}

Theories of cognition are closely aligned with theories of intelligence and the measurement of intelligence. It has always been controversial as to what "intelligence" contains, and how much of it is the result of heredity, and how much is the result of the environment, including the educational environment. Nonetheless, the objective is to understand what is innate ability, and to separate that (or to determine its inseparability from) particular content domains.

One of the earliest view of intelligence, due to Spearman in the early 1930s, was that there was only one component of intelligence, which was general intelligence, or $g$. A competing view, due to Thurstone, was that intelligence consisted of several independent factors, and should be measured as such. Further work by Guilford in the 1950s indicated that just about everything measured by commonly-used intelligence tests pertained to convergent intelligence; creative thinking involved divergent intelligence which was typically missed in measurement batteries. The objective of convergent thinking is to find the one correct answer, or the best answer of the options available. Examples include: numerical computation; memory for ideas, sights, sounds, and events; word choices and interpretation; interpretation of a set of logical propositions; or the conversion of one set of symbols into another set. The goal of divergent thinking is to come up with many possible solutions, answers, or options. Often the more unique or aesthetically pleasing responses are given preference. Examples include producing many possible adjectives that could be used to describe a given object, organizing and reorganizing a set of objects into categories, producing novel uses for common objects, drawing analogies between one relationship and another, and suggesting possible consequences of an unusual but significant event. The current landing point is the triarchic theory of intelligence, due to Sternberg, which holds that intelligence contains three broad components: convergent thinking, divergent thinking, and the ability to learn from one's experience.

Applications of NDS to cognition have taken a few distinctive approaches. Goertzel (1993a, 1993b, 1994, 1997) developed computer simulations of cognition with the objective of integrating as many components of the psyche as possible. Here we find systems and subsystems of logic with feedback loops that sustain or alter the logical sets. Perhaps his most poignant finding (1994) is the existence of "chaotic logic" by which irrational belief systems are held in place by strategically organized loops that prevent the illogical system from unraveling. The external validity of the models to actual human thought processes has not yet received experimental attention.

Hardy (1998) studied semantic lattices in verbal cognition. A semantic lattice is a network of mental elements found in memory. The network is organized through associations between a characteristic of an idea and other ideas that share the same characteristic. A semantic lattice, furthermore, is thought to be organized into modules, which Hardy (1998) calls semantic constellations. For instance, if we were to think of two people, e.g., John and Mary, we can immediately connect to everything we know about John, his job, preferences in clothing and food, his car, and so forth. We can do the same with Mary, the relationship between John and Mary, and their 
relationships with everyone else in their social network. According to this line of evolving theory, the percolation and growth of a lattice is based on attractor strength, bifurcations, and self-organization. Although much of the supporting argument for the theory comes from experimental pre-NDS psychology, the empirical verification of the literal dynamics has not yet been observed.

Other productive lines of thought in NDS involve autonomous agents and collective intelligence. Autonomous agents are self-organized configurations of perception, cognition, and action; the special ingredient here is that the search for stimuli and the actions taken are intentional (Guillot and Meyer, in press; Tschacher and Dauwalder, 1999). The formation of agents, as well as the percolation of semantic lattices, can be better appreciated with a brief discussion of the processes of assimilation and accommodation discussed below in the section on human development.

Collective intelligence may be considered a social process as well as cognitive process insofar as ants and bees are social insects. Here we consider the cognitive substance of the phenomenon, as did Sulis (1997, 1999). The important attribute of the phenomenon is that a colony of ants will engage in coordinated activities such as hunting for food in repeated forays to different locations, maintenance of the nest, and reassigning labor to tasks as needed. Ants do so without any one ant having any apparent knowledge or cognitive picture of the entire plan. In other words, the local interaction among ants gives rise to a self-organized collective behavior.

\section{Human Development}

Developmental psychology is concerned with the changes in human cognition, social behavior, and physical development across the life span. The three domains are related, of course. Theories of development have often involved a stage process which comprise a hierarchical series of abilities and behaviors. The three basic principles of stage theories are: (a) Each stage is qualitatively different from each other stage. (b) Each stage in the series is progressively more complex than the previous stage. (c) Each person goes through an invariant sequence of stages. There has been some lively debate over the years regarding whether stages are really as discrete as their proponents claim, whether stages of social and cognitive development are as synchronized as they might appear to be, or whether discrete stages really exist in some aspects of development. Furthermore, stage theories tend to focus on the innate unfolding of cognitive, social, or behavioral schemata, and the relative contribution of the environment needs to be considered as well. The latter counterpoint has become known as the nature versus nurture controversy.

NDS studies in human development have to date centered primarily on the cognitive and motor development of young children. Much of the coordination of limbs, as in learning to walk, is a self-organizing process that begins at the local level of limbs rather than beginning from a central plan that was somehow encoded in the brain. The self-organization process is similar that invoked by Kelso (1995) in his work on multistable responses. Importantly, the sequence of motor development stages displays substantial individual differences among children (Metzger, 1997; Thelen and Smith, 1994; Turvey and Carello, 1995).

Metzger (1997) mentioned that progress in cognitive development studies is limited by the availability of a set of cognitive measurements applicable to development. Nonetheless there has been some recent progress in the area of cognitive development. In one of the better-accepted stage theories, due to Piaget, the developing child interprets the world and makes responses using a process of assimilation or accommodation. Assimilation is the first response of the child to interpret and respond using existing behavioral and cognitive sequences (schemata). When the existing repertoire is not longer adequate, the child responds by accommodating the new situation by developing one or more new schemata. Feldman, Csikszentmihalyi and Gardner (1994) observed 
that the process of assimilation, accommodation, and eventual cognitive growth is essentially a selforganization process. Partridge (in press) observed further that the accommodation and assimilation process is a fundamental phenomenon of complex adaptive systems. He observed, furthermore, that the operating individual characteristic is temperament, which is a child's proclivity to engage in a new situation or approach another person, to avoid, or to delay before approaching. The approach-avoidance process is thought to be the primary driver in environmental interaction, which in turn facilitates or retards the assimilationaccommodation process. The transition between stages is a gradual increase of a new response and a gradual phasing out of an old response. The two gradients of behavior change, however, cross at a critical point, producing discontinuous responses similar to those found in catastrophe models.

The approach-avoidance dynamic lends itself to dynamical modeling. That is considered in the broader context of the motivation models presented in the social and organizational psychology section of this article.

\section{SOCIAL AND ORGANIZATIONAL PSYCHOLOGY}

This group of topics includes social cognition, motivation, interpersonal attraction, attitudes, and several other topics of occupational relevance. Creativity, which has an important cognitive component, is included here largely because of the group dynamics that are also part of the process.

\section{Motivation}

Psychological theories of motivation have taken many forms over the years. Hunger and thirst predispose animals to behave as desired in learning experiments. If the rat knows where the cheese is, we can leap quickly to cognitive theories of motivation, due to Vroom, whereby the decision maker chooses behavior options that will produce the desired expected reward levels. There is also a theory of equity, due to Adams, in which the agent takes action to restore or maintain equity with other agents.

Another important theme that pervades many social and organizational theories of motivation is the distinction between intrinsic and extrinsic motivation. Extrinsic motivation and extrinsic reward describe situations where the agent receives reward from an outside source. It contrasts with intrinsic motivation, where the agent receives reward, usually intangible, from the activity itself. Examples of intrinsic motivation would include the motives for achievement, affiliation, and power.

Physiological motivation consists of only one form, which is arousal. Arousal originates in the reticular formation of the brain, transfers to the thalamus, and transfers again to the cortical areas where it is interpreted. The same essential process applies to emotion as well; NDS studies of emotion are included in the personality and clinical sections of this article.

The butterfly catastrophe model of motivation in organizations draws together many of the previously-known dynamics affecting personnel selection and training, motivation, and work performance, absenteeism, and turnover (Guastello, 1981, 1987, 1995; Fig. 4). The principles of several motivational theories are represented in the model. The butterfly catastrophe model consists of three stable states of performance and four control parameters. The four control parameters are ability (asymmetry), extrinsic motivation (bifurcation), intrinsic motivation (swallowtail), and a management climate that tolerates individual differences and encourages intrinsic motivation to dominate over extrinsic motivation (butterfly). Although all parts of the model, including the butterfly structure itself, have been empirically verified, it should be noted that some practical applications of this model may involve only subsets of the butterfly dynamics.

The gradients on the butterfly responses surface that run between the stability points and the point of degenerate singularity are interpretable as 


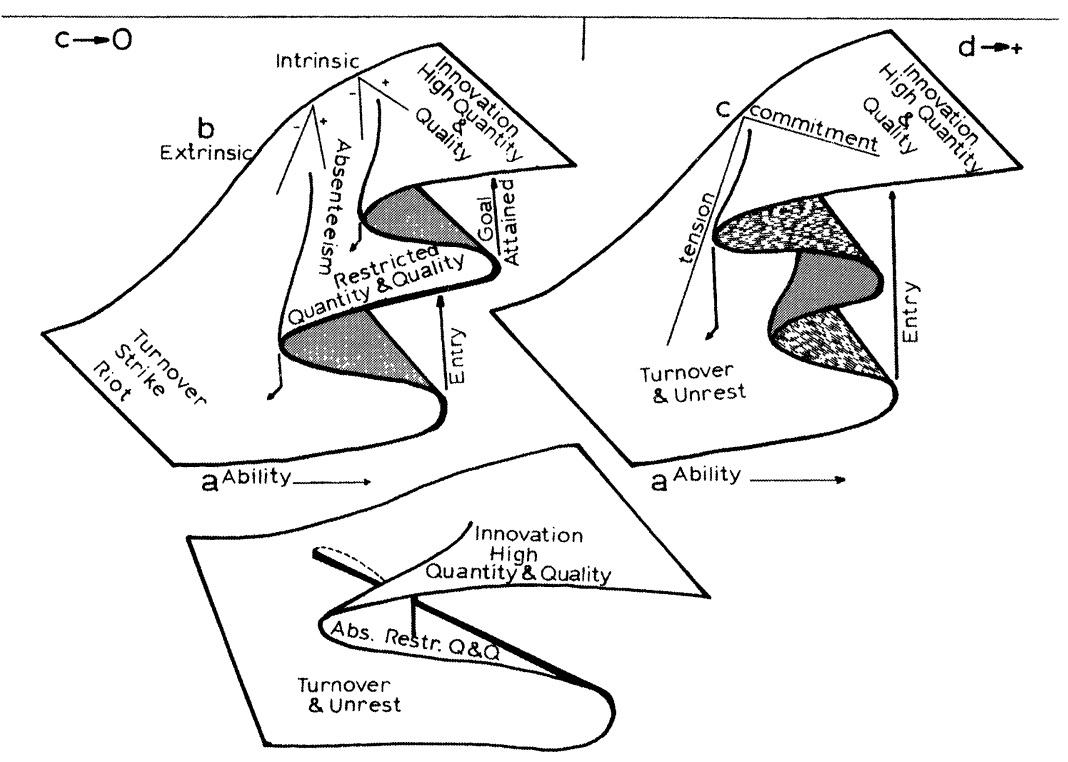

FIGURE 4 Butterfly catastrophe model of motivation in organizations. Reprinted with permission of the American Psychological Association.

approach and avoidance gradients in motivation theory. If one were to define a more complex dynamical field, such as having many jobs to choose from, the dynamics become progressively more complicated (Abraham, 1995; Guastello, Johnson and Rieke, 1999).

\section{Social Cognition}

Vallacher and Nowak (1994, 1997) and their contributors prepared a foundation for studying phenomena known to social psychologists. Attitudes, social judgments, and social relationships change over time, but conventional psychology has been, at best, clumsy about representing the temporal character of social events. Correlational dimensions that vary across experimental conditions, analyses of attractors and stability, catastrophes, and cellular automata are all promising tools in this regard.

As an example, Latané and Nowak (1994) examined the diffusion of an attitude change attempt in a hypothetical population. The cellular automata results (Fig. 5) reflect the effect of physical proximity of one cell, representing 400 people, to another. The results of the diffusion process were consistent with mathematical predictions from earlier social theory.

\section{Interpersonal Attraction}

People are attracted to each other for all sorts of reasons; an extensive summary of reasons is beyond the scope of this article. Nonetheless, once two people find that they have something in common, the forces of approach-avoidance and cooperation-competition then ensue. In the particular case of romantic relationships, the time evolution of the relationship can be volatile or not, depending on the strength of the attraction and propensity toward avoidance. In Figure 6 Rinaldi and Gregnani (1998) model the phase portrait of the mutual attraction for robust and fragile couples. For robust couples, there are simple rather than multiple saddle points.

When enough people join the social group, a network of relationships forms. The evolution and stability of networks depend on the intimacy, intensiveness, and exclusiveness, of the relationships. Alisch, Azizighanbari and Bargfeldt (1997) 

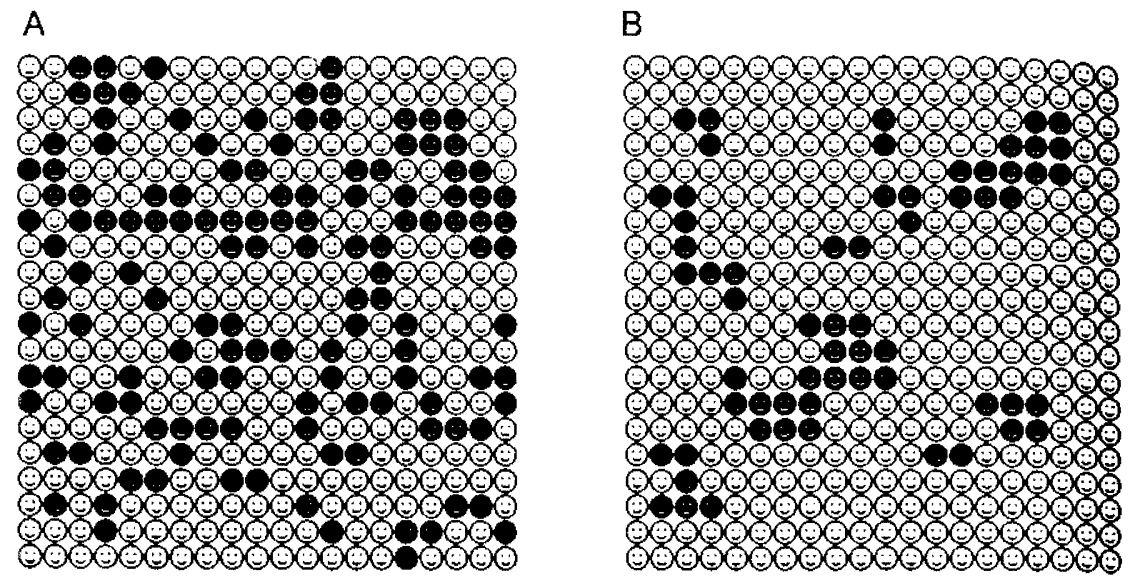

FIGURE 5 Spatial distribution of attitudes before (A) and after (B) social influence. Faces reflect one of two attitudinal positions (from Latané and Nowak, 1994, p. 244).
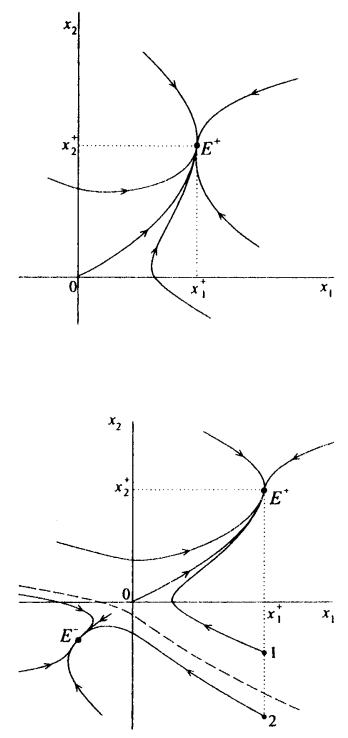

FIGURE 6 Dynamical fields for robust (upper) and fragile (lower) couples for varying initial conditions (from Rinaldi and Gragnani, 1998, p. 291).

have been working on simulations of children's friendship networks based on those three variables using 3-D phase portraits.

\section{Creative Problem Solving}

Creativity is recognized as a complex phenomenon involving divergent thinking skills, some personality traits that are commonly associated with creative individuals across many professions, an environment rich in substantive and interpersonal resources, and cognitive style. Cognitive style is a combination of personality and cognition; it refers to how people might use their talents rather than the quantity of such talents. According to an early version of the "chance-configuration" concept (Simonton, 1988), creative products are the result of a random idea generation process. 
Greater quantities of ideas are generated from enriched personal and professional environments. Idea elements recombine into configurations as part of the idea generation process. When the creative thinker latches on to a new configuration and explores it as a possible solution to a problem, a form of self-organization of the idea elements takes place.

In the context of nonlinear dynamics, however, the generation and recombination of idea elements is chaotic rather than random. The self-organization of idea elements is largely a response to a chaotic system state. The idea elements, meanwhile, are generated by determined, human systems, whether individually or in groups. The individuals filter out some ideas and attract others depending on their goals for problem solving. They also organize idea elements according to their own unique mental organization and experience; some of these mental organizations are shared with other people, and other problem solvers in the group, and other mental organizations are not so shared. The process of idea generation retraces the paths that the individuals have mentally created already among idea elements, prior to any one particular problem-solving event (Guastello, 1995, 1998a).

The mushroom (parabolic umbilic; Fig. 7) catastrophe was found to explain the dynamics of creative problem solving in groups who were working together in real time in an experimental situation (Guastello, 1995). The response surface represents two interacting clusters of social interaction patterns. General Participation included information giving, asking questions, and statements of agreement with other people's ideas; it was found to be a bistable variable. Especially Creative Participation included statements that initiated courses of action for the group, elaboration of ideas, and rectifying intellectual conflicts; it displayed one stable state with instability at the high contribution end of the scale.

Two of the four system control parameters, both of which were asymmetry variables, were occupied by personality traits. One cluster of traits distinguished high-production participants from lowproduction participants on the factor for general contributions. Assertiveness distinguished those who most often gave especially creative responses from others. The two bifurcation control parameters were overall group activity level, which captured a social dynamic, and the effect of particular experimental stimuli, which captured an environmental contribution. The news bulletins were introduced periodically as part of the game; they contained unexpected changes in the problem situation that should provoke an adaptive response from the players.

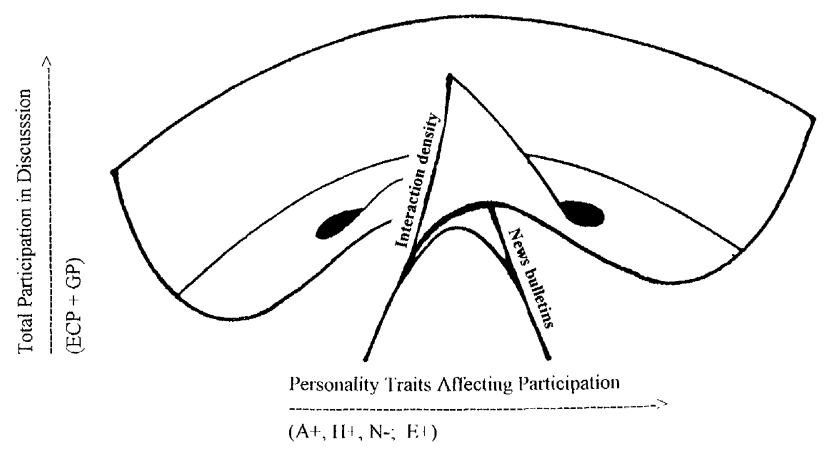

FIGURE 7 Mushroom catastrophe model for creative production in problem solving groups. $\mathrm{ECP}=$ Especially Creative Participation; $\mathrm{GP}=$ General Participation; $\mathrm{A}+=$ warmth and participativeness; $\mathrm{H}+=$ social boldness; $\mathrm{N}-=$ unpretentiousness; $\mathrm{E}+=$ assertiveness. "News bulletins" are experimentally applied shocks that were specific to the problem the group was trying to solve. 
The mushroom structure itself was verified through a polynomial regression technique. In this case, a nonlinear regression technique was also used for estimating a Lyapunov exponent, which was positive and translated into a dimensionality of 5.46. This high dimensionality, which is also fractal, was an important observation because, according to the emerging theory, chaos leads to self-organization, and as creative self-organized systems engender more instability, it would follow that creative problem solving groups are systems operating at the edge of chaos.

Recent studies have also explored whether computer-facilitated communication can enhance the group's overall level of production compared to the production of a collection of noninteracting individuals, so long as the group is large enough to produce a critical mass of ideas. Computer media can facilitate chaotic levels of idea production. In this situation, "chaotic" refers to bursts of high and low idea production over time, on the part of either individuals or groups. Additionally, greater amounts of variability in production on the part of an individual are associated with greater quantities of ideas that are produced by other group members in between two successive inputs from a particular person. These dynamics conform to the logistic map structure (Guastello, 1995).

At the group level of analysis, greater productivity is associated with a relatively complex problem task, where the task can be broken down into subtopics. At that time the group members can work on any subtopic in any order they choose, go back and forth among the subtopics, and so on. In the actual groups studied (Guastello, 1998a), the number of active topics increased and decreased in a periodic fashion. The level of output by the group was chaotic overall, but it also showed periodic rises and drops in activation level in accordance with the change in the number of active topics. Thus the result, in the thinking of synergetics, is a coupled dynamic consisting of a periodic driver

$$
A_{2}=0.75 A_{1} \mathrm{e}^{(-0.36 A 1)}+0.33,
$$

and a chaotic slave

$$
Z_{2}=\mathrm{e}^{(0.25 z 1)}+0.43 A-0.26 C-0.34 .
$$

In Eqs. 4 and 5, $z_{i}$ represents group production levels can be observed depending on the topic that the group is working on $(C)$; and, $A$ is the number of active discussion threads during the time interval of $z_{1}$; time was measured in 4-day periods. The exponent in Eq. (6) was negative, and the exponent in Eq. (5) was positive.

\section{Leadership Emergence}

The rugged landscape model of self-organization has been received increased attention lately as an explanation for organizational phenomena, particularly where strategic management is involved (McKelvey, 1999). The rugged landscape model of self-organization explains how leaders emerge from a leaderless group, and the possible ways in which their emergence could take form (Guastello, 1998b; Zaror and Guastello, 2000). The group activity selected for study involved a complex creative problem solving task. Once presented with the task and an hour (of experimental time) to complete it, numerous verbal interactions transpire among group members. These local interactions are thought to culminate in the eventual self-organization of the group such that the role of a general leader emerges along with several other, more specific roles. This form of differentiation had been reported without the non-NDS concepts in personality studies of emerging leaders decades beforehand.

The formation of roles would constitute fitness peaks, which denote relative fitness, local stability, and clusters of similar subspecies with regard to shared adaptive traits. The probability density function that is associated with the swallowtail catastrophe model (Eq. (8)) describes the distribution of people into unstable and locally stable social roles. The swallowtail catastrophe structure contains a response surface of discontinuous events, or qualitatively different outcomes, such 
that there are two stable states, with a minor antimode between them, an unstable state, and a major antimode separating the unstable state from the two stable ones.

$$
\operatorname{pdf}(z)=\xi \exp \left[-\theta_{1} z^{5}+\theta_{2} z^{4}-\theta_{3} c z^{3}-\theta_{4} b z^{2}-\theta_{5} a z\right]
$$

In Eq. (8), $z$ is the extent to which members of the group endorse a particular group member as the leader; $a, b$, and $c$ are control parameters; $\xi$ is a constant that maintains unit density; and $\theta_{i}$ are nonlinear regression weights. Research is currently continuing in the direction of identifying the control variables in different types of work situations.

McClure (1998) is working on similar ideas, but with both task and therapy groups in mind. $\mathrm{He}$ emphasizes the importance of the content of conversations for inducing desired outcomes for the group.

\section{Work Group Coordination}

One important problem in group productivity is that the quality of the outcome for a group is not consistently better than the outcome or product from the most talented individual in the group. Psychologists have found partial remedies and explanations for this phenomenon by defining the task as a group task, allocating rewards to the group rather than to individuals, and defining responsibilities to prevent social loafing, and enhancing group cohesion. The differential productivity problem still persists, nonetheless, and the internal dynamics of group workers is the current point focus of NDS research (Guastello, Bock and Caldwell, 1999; Guastello and Guastello, 1998).

Coordination occurs when group members make the same or compatible responses at the right time for optimal production. In game theory, there are several distinct forms of coordination; the type described here is based on the four-way stop intersection. If the drivers correctly perceive the turn-taking system adopted by the preceding drivers and follow the sequence, then all cars pass through the intersection in a minimum amount of time with the lowest odds of a collision. In a reallife intersection, any of several possible rule systems could be adopted by the drivers, and each driver approaching the intersection needs to observe the strategy that is actually in effect, then make the correct move. If a car tries to go through the intersection out of turn, then an accident could occur, or at the very least, other players would need to revert to ad lib turn-taking to untangle the confusion at the intersection.

The process of group coordination involves the development of nonverbal communication links among the participants. These links evolve with repeated practice with each other. The evolution of the links is essentially a self-organization process. Furthermore, the basic process of coordination is non-hierarchical, meaning that a leader, who usually contributes task structuring activities of some sort, is not required. This state of affairs is not unlike the flocking of birds, herds of beasts, or schools of fish, which operate without leaders.

The results of experiments to date show that if the experimental task is not excessively difficult, the group will display a coordination learning curve. The coordination acquired during one task session will transfer to the learning and performance curve of a second task. If the task is too difficult, self-organization will not be complete, and the time series of coordination data will be chaotic. Verbalization enhances performance to some extent. A coordinated group can withstand changes in personnel up to a point before coordination breaks down.

\section{General Perspective on Management}

Some of the organizational literature focuses attention on the broad concept of the organization as a whole entity and the implications for management. One line of thinking emphases the contrasts between systems thinking and the nonlinear dynamics of change against the mechanistic and static view of conventional management (Kiel, 
1994; Thietart and Forgues, 1995; Anderson, Meyer, Eisenhardt, Carley and Pettigrew, 1999). Another considers how strategic management is best accomplished for a complex adaptive system (Dooley, 1997; McKelvey, 1999; Stacey, 1992). A third line of thinking emphasizes practical ways for inducing entropy for organizational change and means by which managers can develop intuitive understandings of nonlinear organizational dynamics (Eoyang, 1997; Goldstein, 1994; Wheatley, 1992; Zimmerman, Lindberg and Plsek, 1998).

\section{PERSONALITY AND CLINICAL PSYCHOLOGY}

The area of personality and clinical psychology is concerned with theories of the normal range personality, the etiology and treatment of psychopathology, and related topics. Some of the prominent theories in psychology have devoted more attention to the pathological side of human nature, while others have had the opposite emphasis, which is to maximize mental health and the human condition. The contributions of NDS have addressed concepts that were initially framed by a variety of different psychological schools of thought. The following summary is based on that "natural" organization of topics.

\section{Classical Psychoanalysis}

The earliest and most comprehensive theory of human personality, pathology, and the treatment thereof came from Sigmund Freud's psychoanalysis at the turn of the 20th Century. The key aspects of the theory were propositions concerning: instincts and the primacy of sexuality and destruction in motivation, levels of conscious awareness, psychic energy, psychic structures and the defense mechanisms of the ego, a theory of psychosexual development, and the psychoanalytic method for diagnosis and treatment. Although Freudian psychoanalysis enjoyed widespread popularity as an operating theory of the psyche and as a treatment method, the theory eventually succumbed to deficits in its ability to explain psychological phenomena adequately. It remains valuable, however, for its historical impact on psychologists who either followed or disagreed with its general principles or specific ideas.

Of interest to NDS is that Freudian psychoanalysis invoked a concept of psychic energy and principles pertaining to energy movement around the psyche. Energy was assumed to limited in quantity, and moving around a closed psychic system according to rules of thermodynamics. To date, no one has ever found, let alone been able to measure, a construct of psychic energy. The thermodynamics principles were consigned long ago to the realm of Quaint Metaphor. Dynamicists are now revisiting Freudian concepts for their dynamical components, and how they might be recycled into contemporary theory (Goldstein, 1995 , 1997). Others have focused attention on the conversation and redirection of thought that takes place in psychotherapeutic sessions (Stein, 1999). Of further interest, the psychological dynamics of motivation and behavior change follow the same mathematical rules as phase transitions for physical materials.

Psychoanalytic theory took a historically interesting turn with the work of Carl Jung. Jung was initially one of Freud's protégés but inevitably had a few ideas of his own: a theory of psychological types based on four variables, the fundamental notion of psychic energy as an unlimited quantity in an open or dissipative system, the assumption that a life force was central to psychic existence instead of sexuality, the concepts of archetypes, and the existence of a racial memory in the unconsciousness. Archetypes are symbolic images that represent some important themes that are found in major mythological systems throughout the world. Archetypes were thought to transfer from generation to generation genetically through the structure of racial memory, and the collective unconscious. For instance, one might observe the visual and conceptual similarities between the 
cupids in Roman art of the first century B.C.E. and the angels depicted in Renaissance art, and consider how they might qualify as an archetype. One might further ruminate on the similarity between symbols and mystical concepts found in European, Egyptian, Hindu, and Chinese mythologies, and hence the credence of a collective unconscious common to all human beings.

Today, scientific psychology does not take the concept of racial memory and its genetic transmission seriously, although the collective unconscious is a bit more palatable. Jung's theory of psychic energy is no more established than Freud's theory of energy. Archetypes might be regarded as special cases of cognitive prototypes. As symbolic objects they remain interesting, but today they are regarded as memes - deeply meaningful idea elements that float around the culture through artifacts, written works, and social structures that maintain interest in their content (e.g., libraries, educational systems, government funding). To his credit, Jung found a bridge between cultural experience and the individual psyche.

The circulation of memes is interesting to contemporary NDS theorists in clinical psychology (Bütz, 1998; Chamberlain and Bütz, 1998) as well as those concerned with broader issues of creativity and culture (Combs and Holland, 1996; Csányi, 1989; Feldman et al., 1994). Others theorists have ruminated on the relationships between fundamental mathematical ideas since the Renaissance and the idea elements captured by many of the principal Jungian archetypes (Robertson, 1995).

\section{Humanistic Psychology}

Humanistic psychology is usually associated with the work of Abraham Maslow, Rollo May and Carl Rogers, which gained prominence in the 1950s and 1960s. Those theorists diverged from their predecessors by aiming at a concept of optimal human functioning and optimal human experience instead of just an escape from psychic trauma and pathological conditions. Their work produced a concept of the self, self-esteem, and self-actualization. Although a concept of self was known in previous times, research was finally generated on the subject, some of which was picked up by experimental social psychologists.

Of importance to this review was the humanists' emphasis on the whole person. Mental health and psychic development require an integrated personal understanding of all the aspects of one's being on the part of the client and therapist. In recent times, after a decade or two of distraction from the humanistic principles, the emphasis on the whole person has evolved into a concept of the person as a complex system in the NDS sense (Bütz, 1998; Chamberlain and Bütz, 1998; Orsucci, 1998; Massimini and Delle Fave, 2000; Schiepek, 1999).

The traditional philosophical counterpoint between free will and determinism takes a new turn with the discovery and understanding of mathematical chaos; the chaos concept must have an impact on the way people are taught to interpret events for themselves, or on behalf of their clients (Mosca, 1995). There is a certain stability to human personality in the form of psychological traits (a long story in contemporary psychology by itself), and at the same time a flexibility in selfconcept that is dependent on us having multiple social roles (another long story). Add in the cultural contributions and the stages of development, and it is compelling to regard the psychological structure of the self as a complex adaptive system (Marks-Tarlow, 1999).

\section{Psychopathologies and Treatment}

NDS theorists have turned some attention and empirical study to the severe psychopathologies such as schizophrenia (Hornero, Alonso, N. Jimeno, A. Jimeno and López, 1999) bipolar disorder (Abraham et al., 1990; Scott, 1985; Thomasson, Pezard, Allilaire, Renault and Martinerie, in press), and psychopathic deviance (Lange, 1999). Others have considered the stability (Clair, 1998; Guastello, 1982; Byrne, Mazanov and Gregson, in press) and symptom complexity 
(Tschacher, Scheier and Grawe, 1998) of outpatient treatments.

In the final category, entire families may present themselves for therapy. The family is now conceptualized as a complex system, and much can be learned by studying the temporal patterns of interactions among family members (Bütz, Chamberlain and McCown, 1996; Koopmans, 1998; Pincus, in press).

\section{SUMMARY}

The word "conclusions" is not a good choice in this context, but a few summary remarks are warranted based on the history and inventory of nonlinear dynamics in psychology presented here. The days of "Here's Chaos!" have been gone for quite some time. The value of NDS concepts and methods for explaining phenomena is being actively explored and tested. All the main areas of psychology have been visited by NDS theory to some extent. A promising development is that NDS can address phenomena that were observed or conceptualized in past theory, but for which a set of modeling concepts and methods was not yet available. What results is an integration of NDS and basic principles in each percolation of psychological theory.

In the cognitive area, it is possible that NDS applications will be instrumental in uniting several aspects of cognition into a comprehensive theory or model of mental processes. In the social and organizational area, the possible outcomes are more diffuse, but there is at least a core of thinking that purports to describe how two people can become connected, then more people become connect to form a networks, cohesive social groups, and groups with differentiated internal structures. In the clinical applications, there is an emphasis on understanding the whole person, and that such an understanding is critical to development of mentally healthy situations.

There are also implications for professional practice in organizations or clinical treatment. The state of practical application is expected to evolve in concert with the theory and methodologies.

\section{References}

Abraham, F. D. (1995) Dynamics, bifurcation, self-organization, chaos, mind, conflict, insensitivity to initial conditions, time, unification, diversity, free will, and social responsibility. In: Robertson, R. and Combs, A. (Eds.), Chaos theory in psychology and life sciences (pp. 155-173). Mahwah, NJ: Lawrence Erlbaum Associates.

Abraham, F. D., Abraham, R. H. and Shaw, C. D. (1990) $A$ visual introduction to dynamical systems theory for psychology. Santa Cruz: Ariel.

Abraham, F. D. and Gilgen, A. R. (Eds.) (1995) Chaos theory in psychology. Westport, CT: Praeger.

Alisch, L.-M., Azizighanbari, S. and Bargfeldt, M. (1997) Dynamics of children's friendships. In: Eve, R. A., Horsfall, S. and Lee, M. E. (Eds.), Chaos, complexity, and sociology (pp. 163-181). Thousand Oaks, CA: Sage.

Anderson, P., Meyer, A., Eisenhardt, K., Carley, K. and Pettigrew, A. (1999) Introduction to the special issue: Application of complexity theory to organization science. Organization Science, 10, 233-236.

Basar, E. (1998) Brain oscillations I. New York: SpringerVerlag.

Basar, E. (1999) Brain oscillations II. New York: SpringerVerlag.

Brookhart, S. (2000) Psychology on campus: Degrees of separation. APS Observer, 13(2), 1, 6-9, 26.

Bütz, M. R. (1998) Chaos and complexity: Implications for psychological theory and practice. Philadelphia, PA: Taylor \& Francis.

Bütz, M. R., Chamberlain, L. L. and McCown, W. G. (1996) Strange attractors: Chaos, complexity, and the art of family therapy. New York: Wiley.

Byrne, D. G., Mazanov, J. and Gregson, R. A. M. (in press). A cusp catastrophe analysis of changes to adolescent smoking behavior in response to smoking prevention programs. Nonlinear Dynamics, Psychology, and Life Sciences, 5.

Chamberlain, L. L. and Bütz, M. R. (Eds.) (1998) Clinical chaos: A therapist's guide to nonlinear dynamics and therapeutic change. Philadelphia, PA: Brunner/Mazel.

Clair, S. (1998) A cusp catastrophe model for adolescent alcohol use: An empirical test. Nonlinear Dynamics, Psychology, and Life Sciences, 2, 217-242.

Clayton, K. and Frey, B. F. (1996) Inter- and intra-trial dynamics in memory and choice. In: Sulis, W. and Combs, A. (Eds.), Nonlinear dynamics in human behavior (pp. 90-106). Singapore: World Scientific.

Clayton, K. and Frey, B. F. (1997) Studies in mental "noise". Nonlinear Dynamics, Psychology, and Life Sciences, 1, $174-180$.

Cobb, L. and Ragade, R. K. (Eds.) (1978) Applications of catastrophe theory in the behavioral and life sciences. Behavioral Science, 23, $291-419$.

Combs, A. (1995) Psychology, chaos, and the process nature of consciousness. In: Abraham, F. D. and Gilgen, A. R. (Eds.), Chaos theory in psychology (pp. 129-137). Westport, CT: Praeger.

Combs, A. and Holland, M. (1996) Synchronicity: Science, myth, and the trickster. New York: Marlowe \& Co. 
Csányi, V. (1989) Evolutionary systems and society: A general theory of life, mind, and culture. Durham, NC: Duke University Press.

Davids, K., Button, C. and Bennett, S. (1999) Modeling human motor systems in nonlinear dynamics: Intentionality and discrete movement behaviors. Nonlinear Dynamics, Psychology, and Life Sciences, 3, 3-30.

Dooley, K. J. (1997) A complex adaptive system model of organization change. Nonlinear Dynamics, Psychology, and Life Sciences, 1, 69-97.

Eoyang, G. H. (1997) Coping with chaos: Seven simple tools. Cheyenne, WY: Lagumo.

Feldman, D. H., Csikszentmihalyi, M. and Gardner, H. (1994) Changing the world: A framework for the study of creativity. Westport, CT: Praeger.

Ferro Milone, F., Minelli, T. A. and Turicchia, L. (1998) Neuron synchronization and human EEG phenomenology. Nonlinear Dynamics, Psychology, and Life Sciences, 2, 21-34.

Freeman, W. (1995) Society of brains. Mahwah, NJ: Lawrence Erlbaum Associates.

Gilgen, A. R. (1995) A search for bifurcations in the psychological domain. In: Abraham, F. D. and Gilgen, A. R. (Eds.), Chaos theory in psychology (pp. 139-144) Westport, CT: Praeger.

Goertzel, B. (1993a) The evolving mind. New York: Gordon \& Breach

Goertzel, B. (1993b) The structure of intelligence: New mathematical model of mind. New York: Springer-Verlag.

Goertzel, B. (1994) Chaotic logic: Language, thought and reality from the perspective of complex systems science. New York: Plenum.

Goertzel, B. (1997) From complexity to creativity: Explorations in evolutionary, autopoetic, and cognitive dynamics. New York: Plenum.

Goldstein, J. (1994) The unshackled organization. Portland, OR: Productivity Press.

Goldstein, J. (1995) Unbalancing psychoanalytic theory: Moving beyond the equilibrium model of Freud's thought. In: Robertson, R. and Combs, A. (Eds.). Chaos theory in psychology and life sciences (pp. 239-252) Mahwah, NJ: Erlbaum.

Goldstein, J. (1997) Embracing the random in the selforganizing psyche. Nonlinear Dynamics, Psychology, and Life Sciences, 1, 181-202.

Gregson, R. A. M. (1992) n-Dimensional nonlinear psychophysics. Hillsdale NJ: Erlbaum.

Gregson, R. A. M. (1995) Cascades and fields in nonlinear psychophysics. Singapore: World Scientific.

Gregson, R. A. M. (1998) Effects of random noise and internal delay in nonlinear psychophysics. Nonlinear Dynamics, Psychology, and Life Sciences, 2, 73-94.

Gregson, R. A. M. (1999) Confidence judgments for discrimination in nonlinear psychophysics. Nonlinear Dynamics, Psychology, and Life Sciences, 3, 31-48.

Guastello, S. J. (1981) Catastrophe modeling of equity in organizations. Behavioral Science, 26, 63-74.

Guastello, S. J. (1982) Moderator regression and the cusp catastrophe: Application of two-stage personnel selection, training, therapy, and policy evaluation. Behavioral Science, 27, 259-272.

Guastello, S. J. (1987) A butterfly catastrophe model of motivation in organizations: Academic performance. Journal of Applied Psychology, 72, 165-182.

Guastello, S. J. (1995) Chaos catastrophe and human affairs. Mahwah, NJ: Erlbaum.
Guastello, S. J. (1998-a) Creative problem solving groups at the edge of chaos. Journal of Creative Behavior, 32, 38-57.

Guastello, S. J. (1998-b) Self-organization and leadership emergence. Nonlinear Dynamics, Psychology, and Life Sciences, 2, 303-316.

Guastello, S. J., Bock, B. R. and Caldwell, P. (1999) Effects of verbalization and personnel replacement on group coordination. Unpublished manuscript.

Guastello, S. J. and Guastello, D. D. (1998) Origins of coordination and team effectiveness: A perspective from game theory and nonlinear dynamics. Journal of Applied Psychology, 83, 423-437.

Guastello, S. J., Johnson, E. A. and Rieke, M. L. (1999) Nonlinear dynamics of motivational flow. Nonlinear Dynamics, Psychology, and Life Sciences, 3, 259-274.

Guillot, A. and Meyer, J.-A. (2000) Chaotic dynamics underlying action selection in mice. Nonlinear Dynamics, Psychology, and Life Sciences, 4, 297-310.

Guindani, F. M. and Salvadori, G. (Eds.) (1998) Chaos, fractals, and models. Pavia, Italy: Italian University Press.

Haken, H. (1999) Synergetics and some applications to psychology. In: W. Tschacher and J.-P. Dauwalder (Eds.), Dynamics, synergetics, and autonomous agents (pp. 3-12). Singapore: World Scientific.

Hardy, C. (1998) Networks of meaning. Westport CT: Praeger.

Hornero, R., Alonso, A., Jimeno, N., Jimeno, A. and López, M. (1999) Estimation of correlation dimension to evaluate cognitive performance in schizophrenia patents using a new computer technique. Nonlinear Dynamics, Psychology, and Life Sciences, 3, 49-64.

Kampis, G. (1991) Self-modifying systems in biology and cognitive science. Oxford, UK: Pergamon.

Kelso, J. A. S. (1995) Dynamic patterns: Self-organization of brain and behavior. Cambridge, MA: MIT Press.

Kiel, L. D. (1994) Managing chaos and complexity in government. San Francisco: Jossey-Bass.

Kohonen, T. (1989) Self-organization and associative memory (3rd edn.). NY: Springer-Verlag.

Koopmans, M. (1998) Chaos theory and the problem of change in family systems. Nonlinear Dynamics, Psychology, and Life Sciences, 2, $133-148$.

Lange, R. (1999) A cusp catastrophe approach to the prediction of temporal patterns in the kill dates of individual serial murderers. Nonlinear Dynamics, Psychology, and Life Sciences, 3, $143-160$.

Latané, B. and Nowak, A. (1994) Attitudes as catastrophes: From dimensions to categories with increasing involvement. In: Vallacher, R. R., and Nowak, A. (Eds.), Dynamical systems in social psychology (pp. 219-249) New York: Academic Press.

MacCormac, E. and Stamenov, M. I. (1996) Fractals of brain, fractals of mind: In search of a symmetry bond. Philadelphia: Benjamins.

Marks-Tarlow, T. (1999) The self as a dynamical system. Nonlinear Dynamics, Psychology, and Life Sciences, 3, 311-346.

Massimini, F. and Delle Fave, A. (2000) Individual development in a bio-cultural perspective. American Psychologist, 55, 24-33.

McClure, B. (1998) Putting a new spin on groups. Mahwah, NJ: Lawrence Erlbaum Associates.

McKelvey, B. (1999) Avoiding complexity catastrophe in coevolutionary pockets: Strategies for rugged landscapes. Organization Science, 10, 294-321.

Metzger, M. A. (1997) Applications of nonlinear dynamical systems theory in developmental psychology: Motor and 
cognitive development. Nonlinear Dynamics, Psychology, and Life Sciences, 1, 55-68.

Minelli, T. A. and Turicchia, L. (1999) Progressive coherence patterns for electroencephalographic phenomenology. Nonlinear Dynamics, Psychology, and Life Sciences, 3, $129-142$.

Mosca, F. (1995) Freedom in chaos theory: A case for choice in a universe without a bottom line. In: Abraham, F. D., and Gilgen, A. R. (Eds.). Chaos theory in psychology (pp. 181-191). Westport, CT: Praeger.

Orsucci, F. (1998) The complex matters of the mind. Singapore: World Scientific.

Partidge, T. (2000) Temperament development modeled as a nonlinear complex adaptive system. Nonlinear Dynamics, Psychology, and Life Sciences, 4, 339-357.

Pincus, D. (in press). A framework and methodology for the study of nonlinear self-organizing family systems. Nonlinear Dynamics, Psychology, and Life Sciences, 5.

Port, R. E. and van Gelder, T. (Eds.) (1995) Mind as motion. Cambridge, MA: MIT Press.

Porter, R. J. and Hogue, D. M. (1998) Nonlinear dynamical systems in speech perception and production. Nonlinear Dynamics, Psychology, and Life Sciences, 2, 95-132.

Pressing, J. (1999) Referential dynamics of cognition and action. Psychological Review, 106, 714-747.

Rinaldi, S. and Gragnani, A. (1998) Love dynamics between secure individuals: A modeling approach. Nonlinear $D y$ namics, Psychology, and Life Sciences, 2, 283-301.

Robertson, R. (1995) Jungian archetypes: Jung, Gödel, and the history of archetypes. York Beach, ME: Samuel Weiser.

Robertson, R. and Combs, A. (Eds.) (1995) Chaos theory in psychology and life sciences. Mahwah, NJ: Erlbaum.

Schiepek, G. (1999) Die grundlagen der systemischen therapie: Theorie, praxis, forschung. Gottingen: Vandenhoeck and Ruprecht.

Scott, D. W. (1985) Catastrophe theory applications in clinical psychology: A review. Current Directions in Psychological Research and Reviews, 4, 69-86.

Seger, C. A. (1994) Implicit learning. Psychological Bulletin, 115, 163- 196.

Simonton, D. K. (1988) Creativity, leadership, and change. In: Sternberg, R. J. (Ed.), The nature of creativity: Contemporary psychological perspectives (pp. 386-426). Cambridge, MA: MIT Press.

Stein, A. H. (1999) Whose thoughts are they, anyway? Dimensionally exploding Bion's "double-headed arrow" into coadapting, transitional space. Nonlinear Dynamics, Psychology, and Life Sciences, 3, 65-92.

Stewart, I. N. and Peregoy, P. L. (1983) Catastrophe theory modeling in psychology. Psychological Bulletin, 94, $336-362$.

Sulis, W. (1997) Fundamental concepts of collective intelligence. Nonlinear Dynamics, Psychology, and Life Sciences, $\mathbf{1}$, $35-54$.

Sulis, W. (1999) A formal theory of collective intelligence. In: Tschacher W. and Dauwalder J.-P. (Eds.), Dynamics, synergetics, and autonomous agents (pp. 224-237) Singapore: World Scientific.
Sulis, W. and Combs, A. (Eds.) (1996) Nonlinear dynamics in human behavior. Singapore: World Scientific.

Ta'eed, L. K., Ta'eed, O. and Wright, J. E. (1988) Determinants involved in the perception of the Necker cubes: An application of catastrophe theory. Behavioral Science, 33, 97- 115.

Thelen, E. and Smith, L. (1994) A dynamic systems approach to the development of cognition and action. Cambridge, MA: MIT Press.

Thietart, R. A. and Forgues, B. (1995) Chaos theory and organizations. Organization Science, 6, 19-31.

Thom, R. (1975) Structural stability and morphegenesis. New York: Benjamin-Addison-Wesley.

Thomasson, N., Pezard, L., Allilaire, J.-F., Renault, B. and Martinerie, J. (2000) Nonlinear EEG changes associated with clinical improvement in depressed patients. Nonlinear $D y$ namics, Psychology, and Life Sciences, 4, 203-218.

Tschacher, W. and Dauwalder, J.-P. (1999) (Eds.), Dynamics, synergetics, and autonomous agents. Singapore: World Scientific.

Tschacher, W., Scheier, C. and Grawe, K. (1998) Order and pattern formation in psychotherapy. Nonlinear Dynamics, Psychology, and Life Sciences, 2, 195-216.

Turvey, M. T. and Carello, C. (1995) Some dynamical themes in cognition and action. In: Port, R. E., and van Gelder T. (Eds.), Mind as motion (pp. 373 - 401). Cambridge, MA: MIT Press.

Vallacher, R. R. and Nowak, A. (Eds.) (1994) Dynamical systems in social psychology. New York: Academic Press.

Vallacher, R. R. and Nowak, A. (1997) The emergence of dynamical social psychology. Psychological Inquiry, 8, $73-99$.

Vickers, D. and Lee, M. D. (1998) Dynamic models of simple judgments: I. Properties of a self-regulating accumulator model. Nonlinear Dynamics, Psychology, and Life Sciences, $\mathbf{2}$, $169-194$.

Vickers, D. and Lee, M. D. (2000) Dynamic models of simple judgments: II. Properties of a self-organizing PAGAN (parallel, adaptive, generalized accumulator network) model for multi-choice tasks. Nonlinear Dynamics, Psychologv, and Life Sciences, 4, 1-32.

Ward, L. M. and West, R. L. (1998) Modeling human chaotic behavior: Nonlinear forecasting analysis of logistic iteration. Nonlinear Dynamics, Psychology, and Life Sciences, 2, $261-282$.

Watters, P. A. (1999) Psychophysiology, cortical arousal, and dynamical complexity (DCx). Nonlinear Dynamics, Psychology, and Life Sciences, 3, 211-234.

Wheatley, M. J. (1992) Leadership and the new science. San Francisco: Berrett-Koehler.

Zaror, G. and Guastello, S. J. (2000) Self-organization and leadership emergence: A cross-cultural replication. Nonlinear Dynamics, Psychology, and Life Sciences, 4, 113-119.

Zeeman, E. C. (1977) Catastrophe theory: Selected papers 1972-1977. Reading, MA: Addison-Wesley.

Zimmerman, B., Lindberg, C. and Plsek, P. (1998) Edgeware: Insights from complexity science for health care leaders. Irving, TX: VRH, Inc. 